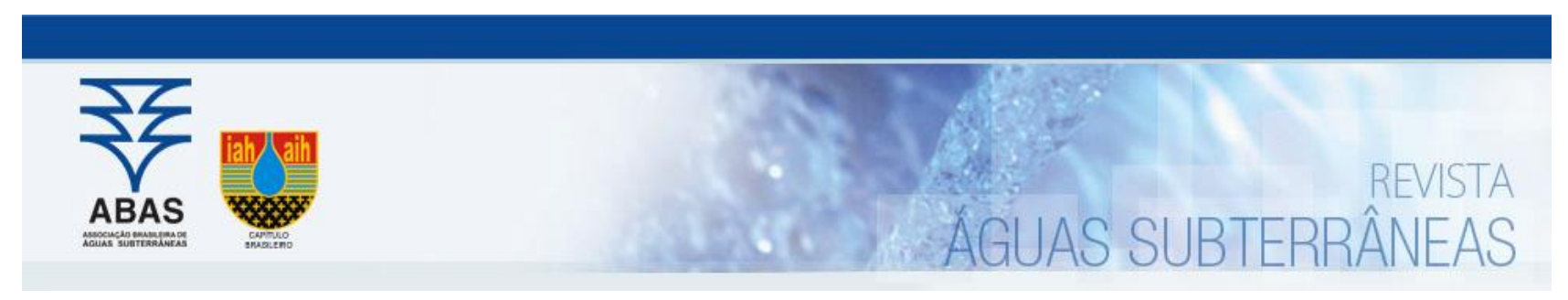

Artigos

\title{
Avaliação do Sistema Aquífero Serra Geral com um modelo de dupla porosidade baseado na análise de testes de bombeamento
}

\section{Evaluation of the Serra Geral Aquifer System with a double porosity model based on the analysis of pumping tests}

\author{
Bianca Regina Severgnini1; Taison Anderson Bortolin; Pedro Antônio Roehe Reginato2 ${ }^{\bowtie}$ \\ 1 Universidade de Caxias do Sul (UCS), Caxias do Sul, RS. \\ 2 Universidade Federal do Rio Grande do Sul (UFRGS), Porto Alegre, RS.
}

$\triangle$ brsevergnini@ucs.br, tabortol@ucs.br, pedro.reginato@ufrgs.br

\author{
Palavras-chave: \\ Aquíferos fraturados. \\ Parâmetros Hidrodinâmicos. \\ Testes de Interferência. \\ Modelos clássicos. \\ Modelos de dupla porosidade.
}

\section{Keywords:}

Fractured aquifers.

Hydrodynamics parameters.

Pumping tests.

Classic models.

Double-porosity models.

Revisão por pares.

Recebido em: 26/01/2021.

Aprovado em: 06/04/2021.
Resumo

O Sistema Aquífero Serra Geral (SASG) é composto por aquíferos fraturados associados às estruturas existentes nas rochas vulcânicas, sendo um sistema heterogêneo e anisotrópico. Por esse motivo, os métodos de Cooper \& Jacob e Theis costumam não ser eficazes em traduzir as descontinuidades do meio e podem levar a avaliações incertas. A utilização de outros métodos, como os de Warren \& Root e de Moench aplicados para aquíferos de dupla porosidade, podem representar uma alternativa para a avaliação desse tipo de aquífero. Dentro desse contexto, o objetivo do estudo foi determinar a eficiência do uso de modelos de dupla porosidade na avaliação de aquíferos fraturados, comparando com os modelos clássicos, através da análise dos ajustes dos dados teóricos aos dados de rebaixamento obtidos em campo. Os dados analisados provêm de testes de bombeamento com poços de observação realizados em uma bacia hidrográfica no município de Caxias do Sul - RS, na qual há a ocorrência do SASG. Os ajustes obtidos através dos métodos de dupla porosidade revelaram que estes apresentam boa adequabilidade no ajuste das curvas de rebaixamento podendo ser empregados para análise de parâmetros hidrodinâmicos de aquíferos fraturados, tal como o SASG. Destaca-se o método de Moench, cujos erros foram 90\% inferiores do que os apresentados pelos métodos clássicos, mostrando que estes últimos são menos eficazes na avaliação do comportamento hidrodinâmico da água em meios heterogêneos e anisotrópicos.

Abstract

The Serra Geral Aquifer System (SGAS) is composed of fractured aquifers associated with the structures existing in volcanic rocks, being a heterogeneous and anisotropic system. For this reason, the methods of Cooper \& Jacob and Theis are not usually effective in translating as discontinuities in the medium and can lead to uncertain assessments. The use of other methods, such as those of Warren \& Root and Moench relative to double porosity aquifers, may represent an alternative for the evaluation of this type of aquifer. Within this context, the objective of the study was to determine the efficiency of the use of double porosity models in the evaluation of fractured aquifers, comparing with the classic models, through the analysis of the adjustments of theoretical data to the data of drawdown obtained in the field. The available data come from pumping tests with observation wells carried out in a small hydrographic basin in the city of Caxias do Sul - RS, in which there is the occurrence of SGAS. Adjustments using double porosity methods revealed that they present good suitability in adjusting the drawdown curves and can be used to analyze hydrodynamic parameters of fractured aquifers, such as the SGAS. The Moench method stands out, the errors were $90 \%$ lower than the previous ones by the classic methods, showing that the latter are less effective in evaluating the hydrodynamic behavior of water in heterogeneous and anisotropic media.

\section{INTRODUÇÃO}

O movimento da água subterrânea ocorre por meio dos vazios interconectados existentes em determinado maciço rochoso, onde a evolução geológica destes determina a classificação dos aquíferos quanto a sua porosidade (SEN, 2015). Conforme Feitosa et al. (2008), a porosidade em um aquífero fraturado pode existir de duas formas: unicamente representada pelas fraturas existentes, quando a matriz rochosa é conside- rada impermeável, ou quando esta possui permeabilidade em conjunto com a permeabilidade das fraturas, chamada de dupla-porosidade. Ainda conforme o autor, aquíferos com duplaporosidade são bastante comuns na natureza, sendo que aquíferos fraturados associados a rochas vulcânicas podem ser considerados como um exemplo, pois, além das estruturas tectônicas (falhas e fraturas), apresentam estruturas geradas pelo resfriamento e estruturação dos derrames vulcânicos.

Cabe ressaltar que esse tipo de aquífero, assim como os aqui- 
feros essencialmente fraturados, são extremamente heterogêneos e anisotrópicos (NEVES; PEREIRA; MORALES, 2002; LIN; LIN; XU, 2014; CRUZ et al., 2019). Essas propriedades tornam o estudo de aquíferos fraturados e, em consequência, de dupla-porosidade, bastante complexo, visto que a heterogeneidade e a anisotropia fazem com que os parâmetros hidrodinâmicos não sejam constantes, podendo, inclusive, variar significativamente em pequenas distâncias (REGINATO e STRIEDER, 2006; FEITOSA et al., 2008; BORTOLIN et al., 2014; DUTRA, 2016; FRENZEL, 2017).

Uma das ferramentas mais utilizadas na caracterização de aquíferos são os testes de bombeamento, pois, além de apresentarem resultados confiáveis quando bem planejados, possuem aplicação relativamente simples (FEITOSA et al., 2008). Feller et al. (2009) citam que esses testes consistem no bombeamento de um poço combinado com o registro do rebaixamento do nível da água tanto no poço bombeado, quanto em um ou mais poços de observação situados a qualquer distância conhecida, desde que dentro do raio de influência do poço bombeado. De posse desses dados, então, é possível solucionar os problemas que envolvem o fluxo subterrâneo.

Os problemas de fluxo de água subterrânea são, usualmente, resolvidos através de equações diferenciais com soluções analíticas. Essas soluções, ao longo do tempo, deram origem a inúmeros modelos teóricos de análise voltados a obtenção de parâmetros hidrodinâmicos e específicos para cada tipo de aquífero, tendo em vista suas condições de contorno e, também, o comportamento dos dados obtidos através dos testes de bombeamento (FEITOSA et al., 2008).

Dentre os modelos clássicos, destacam-se o modelo de Cooper \& Jacob (1946) e de Theis (1935), os quais avaliam o fluxo de água subterrânea em meios homogêneos e isotrópicos e são métodos amplamente utilizados. Devido à simplicidade de aplicação, esses modelos se tornaram referência na análise de testes de bombeamento em variados tipos de aquífero (SUN, 2018; KUANG et al., 2020). É importante destacar que estes métodos foram desenvolvidos considerando aquíferos homogêneos e isotrópicos, o que não ocorre na grande maioria dos casos. Desse modo, a aplicação desses métodos pode levar a avaliações grosseiras das características do aquífero estudado (FERROUD; RAFINI; CHESNAUX, 2019).

Considerando que o fluxo subterrâneo em aquíferos fraturados é extremamente complexo, não é recomendado que estes sejam analisados por meio de modelos clássicos (WATERLOO HYDROGEOLOGY, 2017). Nesse sentido, uma alternativa seria a aplicação de outros modelos, como, por exemplo, os modelos de fraturas discretas ou os de dupla-porosidade como solução para contornar os problemas de descontinuidade, os quais foram desenvolvidos baseando-se na combinação de conceitos básicos, para os quais a análise é realizada através de um conjunto de curvas típicas (FEITOSA et al., 2008).

O modelo de dupla porosidade considera que o fluxo ocorre, primeiramente, do armazenamento do sistema de fraturas e, ao longo do tempo de bombeamento, a água estocada na matriz rochosa começa a ser drenada para as fraturas até que o montante de água captada provenha, em partes iguais, das fraturas e da matriz (WATERLOO HYDROGELOGY, 2017; FERROUND, CHESNAUX e RAFINI, 2018). Os modelos mais conhecidos são os de Warren \& Root (1963) e de Moench (1984), sendo este último o que costuma apresentar os melhores ajustes às curvas obtidas em campo (FIALHO; CHAMBEL; ALMEIDA, 1990; PEREIRA; ALMEIDA, 1997; PAULA; CAMPOS, 2016). Além disso, o modelo de Moench também considera fatores como efeito de pele da fratura, efeito de pele do poço e geometria do bloco da matriz rochosa (PEREIRA; ALMEIDA, 1997; PAULA; CAMPOS, 2016).

Ao analisar a bibliografia disponível sobre o Sistema Aquífero Serra Geral (SASG), percebe-se que a maior parte dos testes de bombeamento utilizam apenas o próprio poço que está sendo bombeado para a realização do monitoramento do nível da água ou, quando muito, há a presença de apenas um poço de observação (BORTOLIN et al., 2014; FRENZEL, 2017; REGINATO, et al., 2018). Além disso, os métodos utilizados para analisar os testes realizados não são, em sua maioria, indicados para sistemas fraturados, como, por exemplo, os métodos de Cooper \& Jacob e de Theis (FEITOSA, et al., 2008). Dessa forma, a avaliação do comportamento real desse tipo de aquífero torna-se praticamente inviável, dificultando a determinação de vazões de explotação, assim como o manejo do armazenamento permanente das reservas e a compreensão da circulação do mesmo.

Dentro desse contexto, o objetivo desse estudo foi avaliar o uso de modelos de dupla porosidade na análise de dados de rebaixamento obtidos no SASG e de comparar os resultados com uso de modelos clássicos através da análise dos ajustes obtidos por tais métodos aos dados de rebaixamento obtidos em campo. Os dados aqui analisados foram obtidos de testes de bombeamento com poços de observação realizados em uma pequena bacia hidrográfica no município de Caxias do Sul - RS, na qual há a ocorrência do SASG, aquífero heterogêneo e de forte anisotropia, conforme já demonstrado por diversos estudos realizados na região (REGINATO; STRIEDER, 2006; BORTOLIN et al., 2014; DUTRA, 2016; FRENZEL, 2017).

\section{MATERIAIS E MÉTODOS}

A área de estudo está inserida em uma pequena bacia hidrográfica no município de Caxias do Sul, na região norte do estado do Rio Grande do Sul. Esta foi selecionada por possuir 3 poços tubulares instalados, os quais são de propriedade da Universidade de Caxias do Sul (UCS) e cujas principais características estão presentes no Quadro 1, enquanto seus perfis encontram-se na Figura 1. Em função da existência de três poços, foi possível realizar os testes de bombeamento num poço e utilizar os outros dois poços para o monitoramento dos níveis de água e rebaixamentos. A possibilidade de monitoramento de dois poços, além daquele que é bombeado, diminui a margem de erro na determinação dos parâmetros hidrodinâmicos. 
Quadro 1 - Dados referentes aos perfis construtivos e outras informações a respeito dos poços analisados neste estudo

\begin{tabular}{|c|c|c|c|}
\hline Poço & 1 & 2 & 3 \\
\hline Tipo & Tubular & Tubular & Tubular \\
\hline Cota & $726 \mathrm{~m}$ & $726 \mathrm{~m}$ & $724 \mathrm{~m}$ \\
\hline Coordenadas (Graus decimais) & $\begin{array}{l}29.161246 \mathrm{~S} \\
51,142686 \mathrm{~W}\end{array}$ & $\begin{array}{l}29,161571 \mathrm{~S} \\
51,142758 \mathrm{~W}\end{array}$ & $\begin{array}{l}29,161662 \mathrm{~S} \\
51,142090 \mathrm{~W}\end{array}$ \\
\hline Data da perfuração & $27 / 06 / 2003$ & $23 / 06 / 2003$ & 29/11/1997 \\
\hline Diâmetro & $150 \mathrm{~mm}$ & $150 \mathrm{~mm}$ & $150 \mathrm{~mm}$ \\
\hline Revestimento & 6" & 6" & Geomecânico 6" \\
\hline Profundidade & $147 \mathrm{~m}$ & $120 \mathrm{~m}$ & $148 \mathrm{~m}$ \\
\hline Altura da boca do poço & $0,5 \mathrm{~m}$ & $0,5 \mathrm{~m}$ & $0,5 \mathrm{~m}$ \\
\hline Profundidade das entradas d'água & 69 e $105 \mathrm{~m}$ & 37 e $81 \mathrm{~m}$ & $78 \mathrm{~m}$ \\
\hline Filtro e pré-filtro & Não há & Não há & Não há \\
\hline Nível Estático & $13,6 \mathrm{~m}$ & $17,72 \mathrm{~m}$ & $16,7 \mathrm{~m}$ \\
\hline Profundidade da bomba & $108 \mathrm{~m}$ & $108 \mathrm{~m}$ & $120 \mathrm{~m}$ \\
\hline Selo sanitário & Existente & Existente & Existente \\
\hline Tubo de inspeção & Existente & Existente & Existente \\
\hline
\end{tabular}

Fonte: Os autores (2020), adaptado de Água Sul Manutenção e Perfuração de Poços Artesianos (2003), Leão Poços Artesianos (1997, 1999).

Os testes de bombeamento dos poços 1, 2 e 3 foram executados na seguinte ordem:

a) Tste de bombeamento 1: bombeamento poço 1; monitoramento poços 2 e 3 .

b) Teste de bombeamento 2: bombeamento poço 2; monitoramento poços 1 e 3 .

c) Teste de bombeamento 3: bombeamento poço 3; monitoramento poços 1 e 2 .

O bombeamento teve duração de 24 horas, com medições de vazão e nível dinâmico ao longo desse período. Além disso, houve também o monitoramento da recuperação do nível dos poços até 180 minutos após o término do bombeamento. Todas as medições foram realizadas nos poços que sofreram o bombeamento e, simultaneamente, nos dois poços de observação para cada teste. Os intervalos entre os testes variaram conforme o período de recuperação dos níveis da água, sendo estes iniciados quando a recuperação atingia um valor próximo ao nível estático anterior ao bombeamento.

A Figura 2 apresenta um croqui com a localização dos poços e a delimitação da pequena bacia hidrográfica de estudo. 
Figura 1-Perfis construtivos e geológicos dos poços

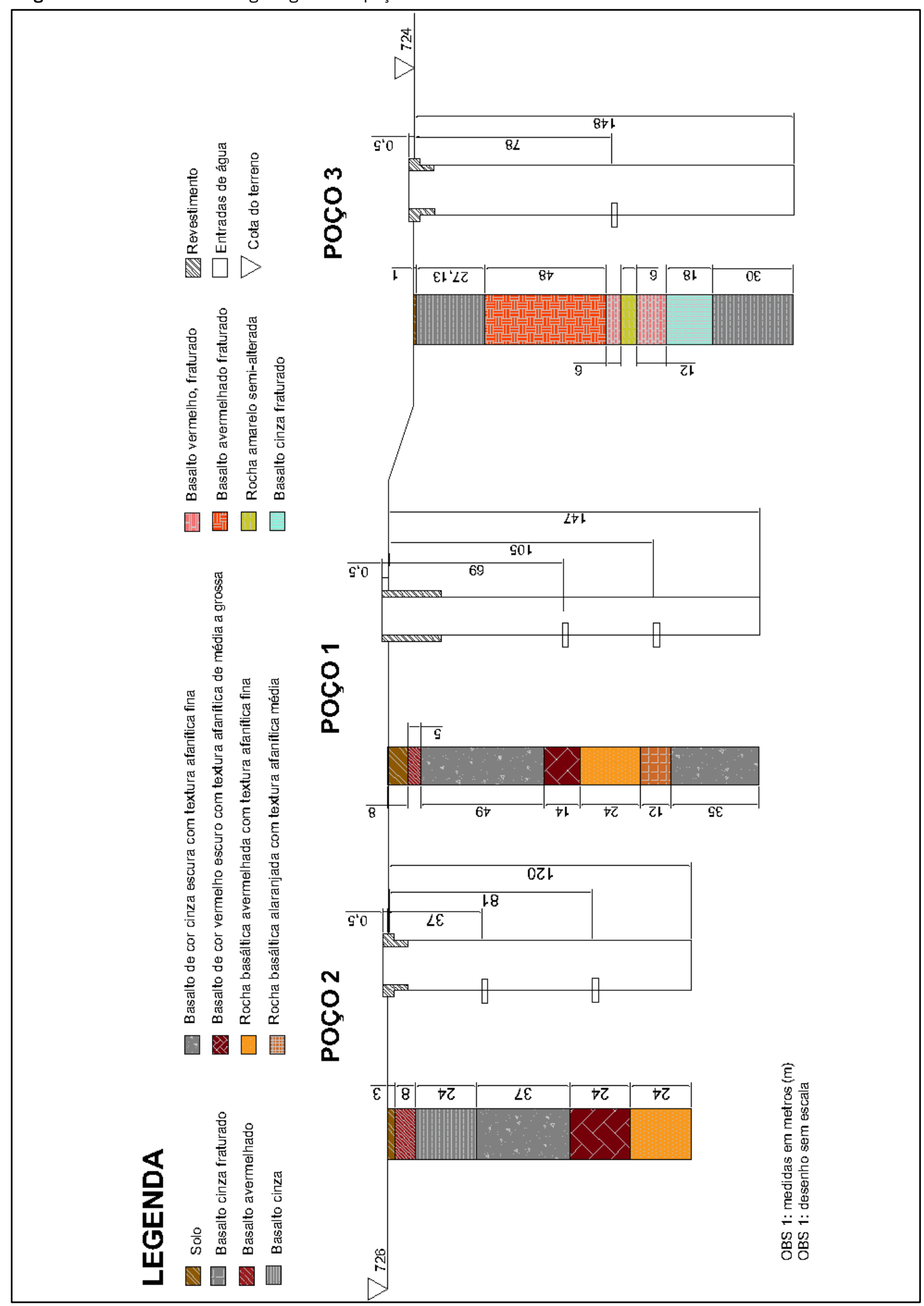

Fonte: Os autores (2020), com base nos dados de Água Sul Manutenção e Perfuração de Poços Artesianos (2003), Leão Poços Artesianos (1997, 1999). 
Figura 2 - Localização do local de estudo
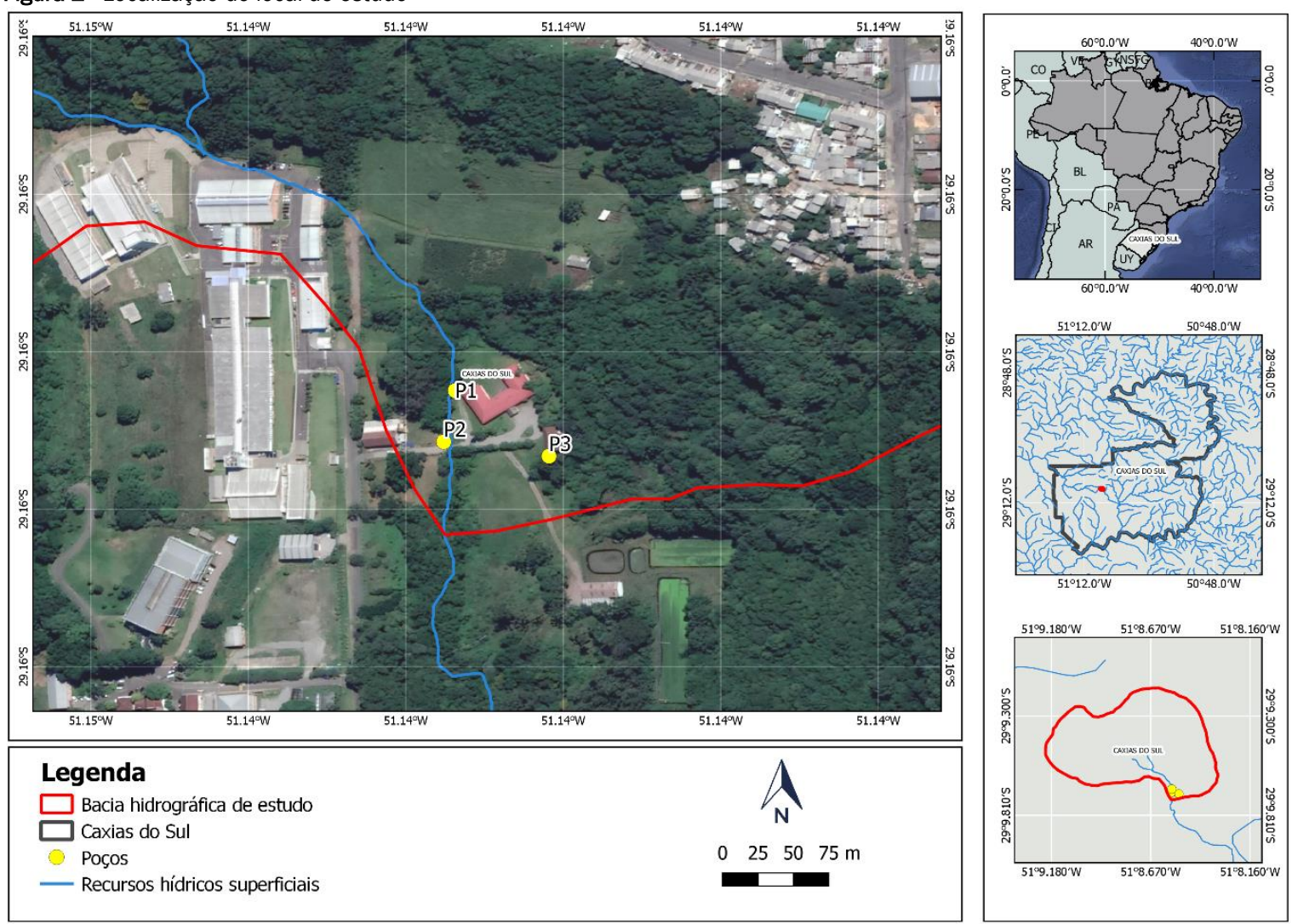

Fonte: Os autores (2020), com base nos dados de Google Earth (2020) e FOREST-GIS (2017).

Os dados dos testes de bombeamento foram utilizados para a avaliação hidrogeológica do Sistema Aquífero Serra Geral. Para o cálculo dos rebaixamentos (s) e das recuperações (s'), em cada tempo medido, utilizou-se a Equação 1, adaptada de CPRM (1998).

$$
s_{(t)}=N E-N D_{(t)}
$$

onde, $s_{(t)}$ é o rebaixamento no tempo $t(m)$; NE é o nível estático da água anterior ao início do teste $(m)$; e $N_{(t)}$ é o nível dinâmico, ou seja, o nível da água no tempo t durante o bombeamento $(\mathrm{m})$.

De posse dos rebaixamentos, foi possível elaborar as curvas de rebaixamento ( $\mathrm{s} x \mathrm{t}$ ) e de recuperação (s' $\mathrm{x}$ te). Para a curva de recuperação foi necessário adaptar os dados de tempo para que esta pudesse ser comparada à curva de rebaixamento, portanto utilizou-se o tempo equivalente de Agarwal (1980).

Para os dados de rebaixamento foram utilizados os métodos de Cooper \& Jacob, Theis, Moench e Warren \& Root. Já para os dados de recuperação os métodos foram: Agarwal Recovery + Theis, Agarwal Recovery + Moench, Agarwal Recovery + Warren \& Root e Recuperação de Theis. Todos os métodos foram trabalhados no software AquiferTest Pro 7.0 (c) (2017) que gera automaticamente o gráfico com os dados dos testes de bombeamento e a curva de ajuste, sendo essa última ba- seada nos resultados de rebaixamento obtidos por cada método aplicado. As curvas obtidas através dos dados coletados em campo foram sobrepostas às curvas teóricas de cada modelo de forma que o melhor ajuste fosse alcançado.

Para a determinação do método que apresentou melhor ajuste e, por consequência, melhores resultados, foi utilizada a técnica estatística denominada soma dos erros quadrados ou soma dos resíduos quadrados. Essa técnica, assim como nome indica, consiste na soma dos quadrados das diferenças entre o valor observado e o valor calculado, conforme Equação 2. A soma dos erros quadrados determina o quanto o fenômeno observado pode ser explicado pelo modelo de regressão e, portanto, quanto mais próxima de zero, menores são os erros e melhor é o ajuste dos dados observados ao modelo (CLASS FINANCIAL ANALYST - CFI, 2020).

$$
S E Q=\sum_{i=1}^{n}\left(y_{i}-\hat{y}_{i}\right)^{2}
$$

onde, SEQ é a soma dos erros quadrados; $y_{i}$ é o valor observado; e $\hat{y}_{i}$ é o valor calculado.

Esse valor foi obtido diretamente através do software AquiferTest Pro 7.0 @ (2017), na opção "estatísticas do ajuste" para os modelos de Theis, Warren-Root e Moench. Porém, considerando que o software não disponibiliza esses dados para os métodos de Cooper-Jacob e Theis Recovery, foi necessária a 
determinação da soma dos erros quadrados por meio do software Excel. Isso foi feito através da plotagem dos dados observados em campo vs. tempo, seguida da determinação da equação da linha de tendência apresentada por estes. Com isso, foi possível calcular os dados de rebaixamento com cada método, separadamente, e assim determinar a soma dos erros quadrados por meio da Equação (2).

\section{RESULTADOS E DISCUSSÃO}

\subsection{Resultados Testes de Bombeamento}

Tabela 1 - Rebaixamentos totais nos poços monitorados durante os testes de bombeamento

\begin{tabular}{ccc}
\hline TESTE DE BOMBEAMENTO & POÇO & REBAIXAMENTO TOTAL $(\mathrm{m})$ \\
\hline \multirow{2}{*}{ TB1 } & $\mathrm{P} 1_{(\mathrm{b})}$ & 9,04 \\
& $\mathrm{P} 2_{(\mathrm{m})}$ & 6,96 \\
& $\mathrm{P} 3_{(\mathrm{m})}$ & 6,98 \\
TB2 & $\mathrm{P} 1_{(\mathrm{m})}$ & 8,32 \\
& $\mathrm{P2}$ (b) $_{(\mathrm{b})}$ & 9,42 \\
& $\mathrm{P} 3_{(\mathrm{m})}$ & 8,41 \\
& $\mathrm{P} 1_{(\mathrm{m})}$ & 8,08 \\
TB3 & $\mathrm{P} 2_{(\mathrm{m})}$ & 8,97 \\
& $\mathrm{P} 3_{(\mathrm{b})}$ & 10,48 \\
\hline
\end{tabular}

(b) poço bombeado

(m) poço monitorado

Fonte: 0 autor (2020).

Tabela 2 - Soma dos erros quadrados dos ajustes das curvas dos testes de bombeamento

\begin{tabular}{|c|c|c|c|c|c|}
\hline Teste de bombeamento & Poço & Cooper-Jacob & Theis & Warren-Root & Moench \\
\hline \multirow{3}{*}{ TB1 } & P1 & 10,569 & 12,359 & 2,341 & 1,635 \\
\hline & P2 & 11,765 & 8,128 & 0,697 & 0,109 \\
\hline & P3 & 13,556 & 8,294 & 0,608 & 0,603 \\
\hline \multirow{3}{*}{ TB2 } & P1 & 17,134 & 16,959 & 2,810 & 2,040 \\
\hline & P2 & 13,215 & 15,105 & 2,358 & 0,729 \\
\hline & P3 & 10,682 & 10,556 & 1,163 & 0,623 \\
\hline \multirow{3}{*}{ TB3 } & P1 & 23,087 & 13,579 & 1,464 & 0,526 \\
\hline & P2 & 17,417 & 11,542 & 1,529 & 0,775 \\
\hline & P3 & 11,182 & 9,679 & 5,022 & 5,018 \\
\hline
\end{tabular}

Fonte: 0 autor (2020).

Nas Figuras 4, 5 e 6 podem ser visualizadas as curvas de rebaixamento individual de cada poço, juntamente com as curvas teóricas de cada método utilizado no estudo. As figuras
Os rebaixamentos dos níveis d'água resultantes da execução dos testes de bombeamento estão presentes na Tabela 1. As somas dos erros quadrados das curvas de rebaixamento obtidas em cada teste de bombeamento para cada poço são apresentadas na Tabela 2 .

As curvas de rebaixamento retornadas tanto pelo poço bombeado quanto pelos poços observados, em cada teste de rebaixamento, podem ser observadas na Figura 3. apresentam os gráficos referente a TB1, TB2 e TB3, respectivamente, e os métodos estão na seguinte ordem: Cooper \& Jacob, Theis, Warren \& Root e Moench. 
Figura 3 - Curvas de rebaixamento dos testes de bombeamento TB1, TB2 e TB3, na sequência

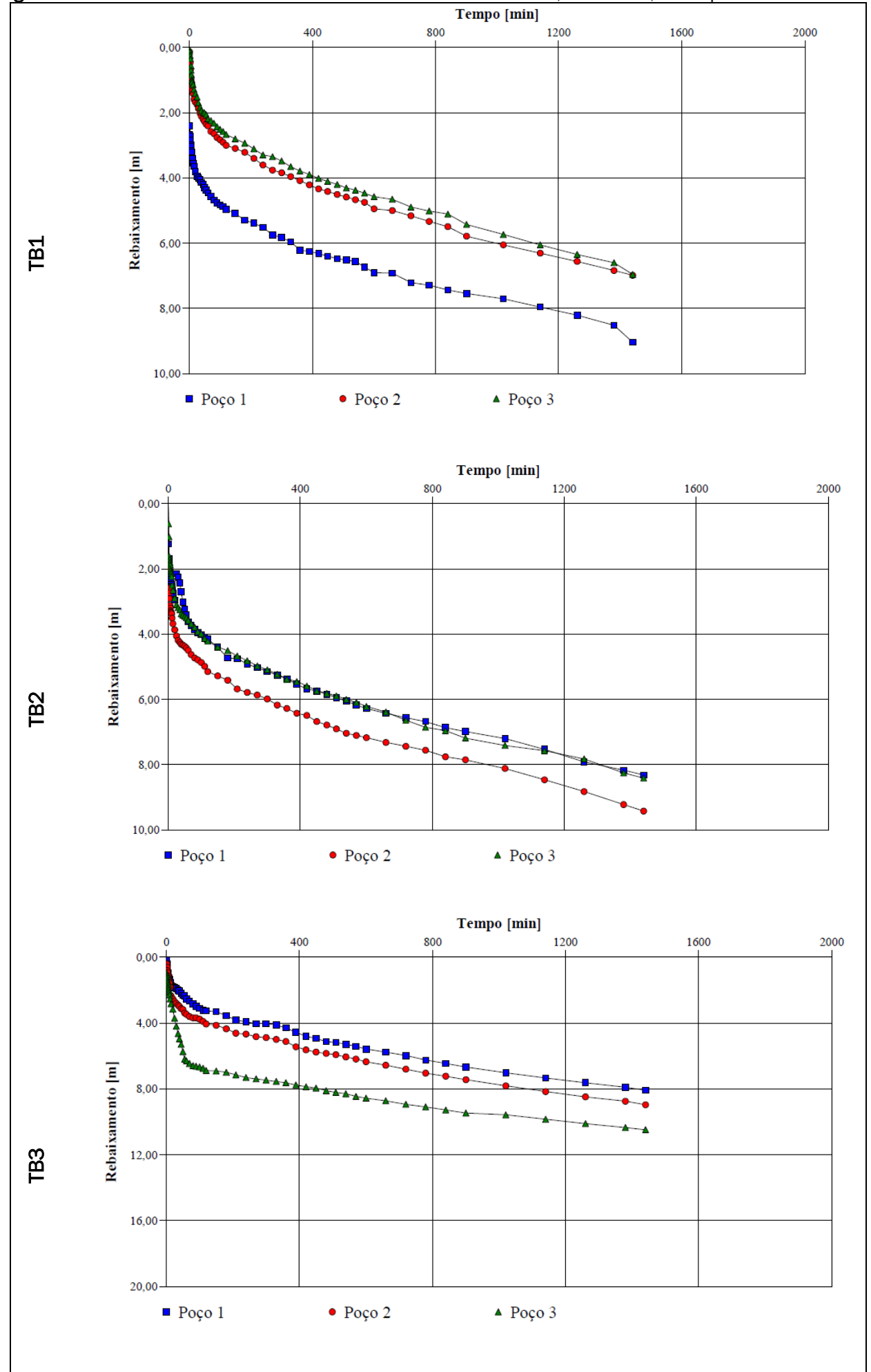

Fonte: Os autores (2020). 
Figura 4 - Curvas de rebaixamento individuais de P1, P2 e P3 e seus respectivos ajustes para os métodos de Cooper \& Jacob, Theis, Warren \& Root e Moench, nesta ordem,em TB1

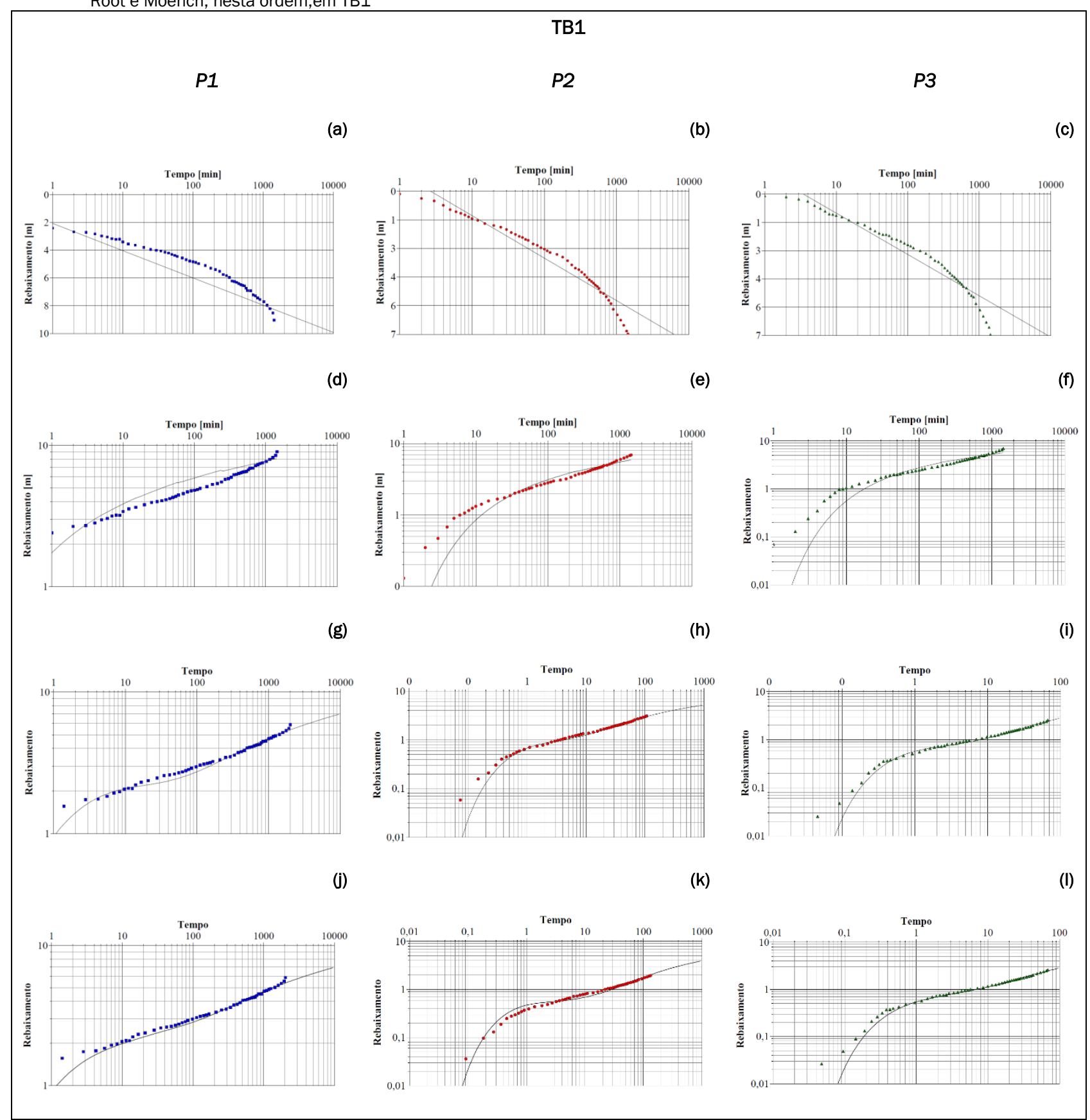

Fonte: Os autores (2020). 
Figura 5-Curvas de rebaixamento individuais de P1, P2 e P3 e seus respectivos ajustes para os métodos de Cooper \& Jacob, Theis, Warren \& Root e Moench, nesta ordem, em TB2

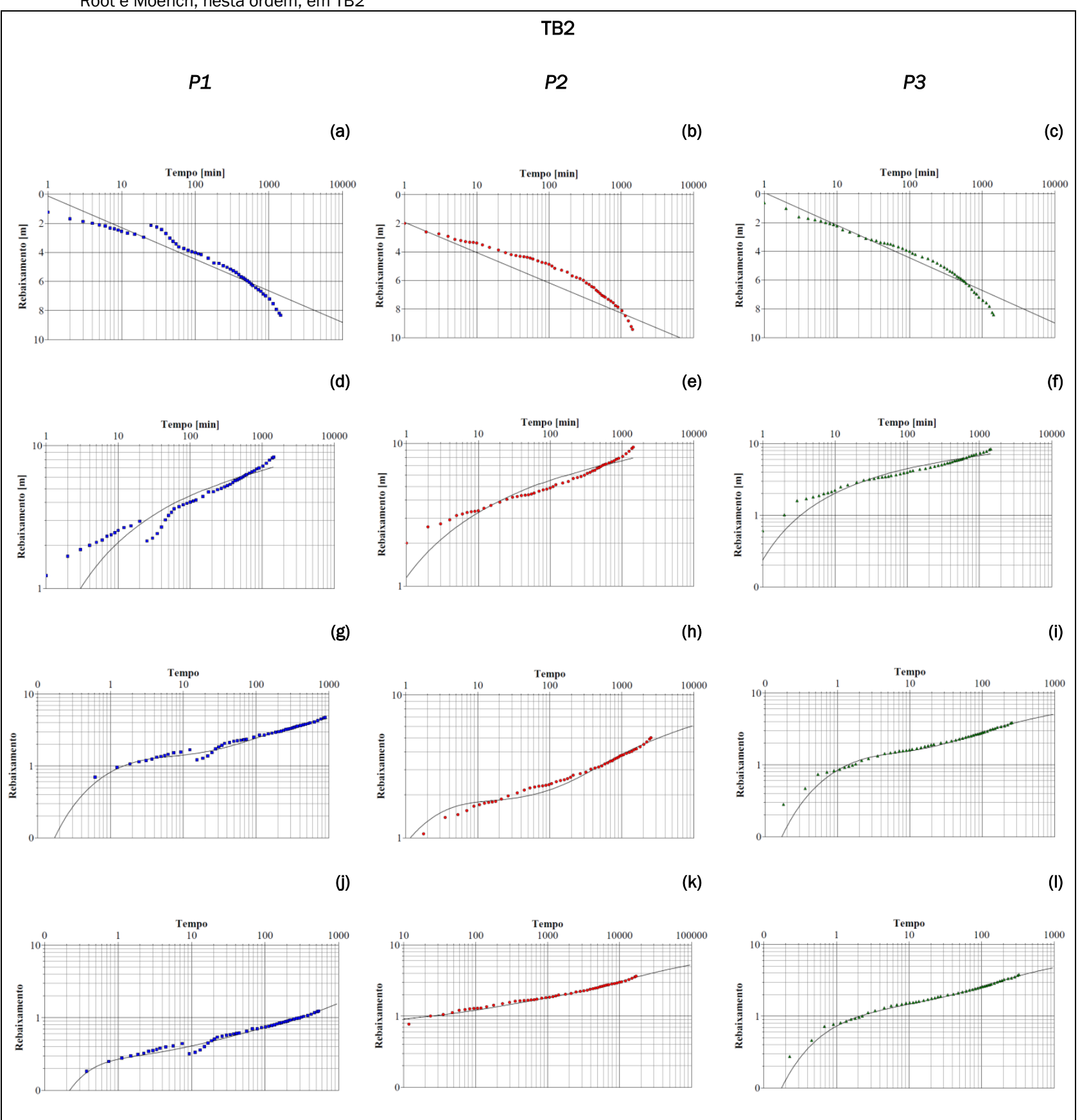

Fonte: Os autores (2020). 
Figura 6-Curvas de rebaixamento individuais de P1, P2 e P3 e seus respectivos ajustes para os métodos de Cooper \& Jacob, Theis, Warren \& Root e Moench, nesta ordem, em TB3

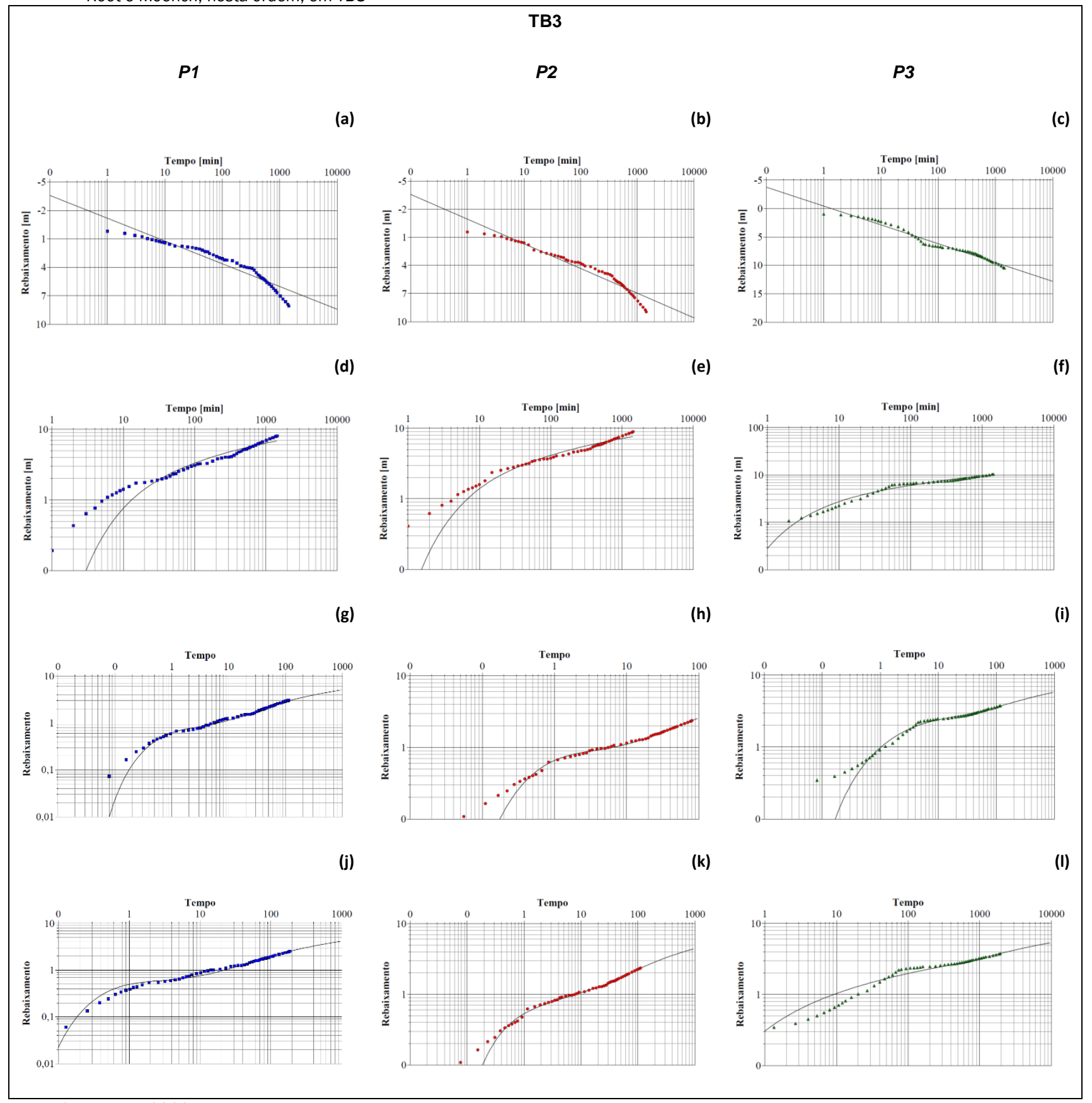

Fonte: Os autores (2020).

\subsubsection{Discussões sobre os Testes de Bombeamento}

Através dos resultados apresentados na Tabela 2, percebe-se que o método que demonstrou, em geral, os melhores ajustes foi o de Moench. Já o modelo de Warren-Root, também específico para aquíferos de dupla porosidade, apresentou erros ligeiramente superiores aos deste, em sua maioria. Com essa constatação, pode-se considerar como uma alternativa viável o emprego dos modelos de dupla porosidade na avaliação de aquíferos fraturados.

A principal diferença entre os dois métodos supracitados é a inclusão do chamado efeito de pele pelo método de Moench
(PEREIRA; ALMEIDA, 1997; PAULA; CAMPOS, 2016). Nas curvas geradas por ambos os modelos há predominância de erros mais elevados nos primeiros momentos dos testes, tal como pode ser observado nas Figuras 6(h) e 6(k), por exemplo. Para os poços que sofrem o bombeamento isso pode ocorrer devido ao armazenamento do poço, onde o rebaixamento inicial se dá devido ao volume de água ali estocado (AHMED; MCKINNEY, 2005). Entretanto, é possível identificar que o método de Moench alcança resultados mais próximos dos dados de campo, quando comparado ao de Warren-Root, principalmente nesse período. Dessa maneira, pode-se presumir a possível ocorrência de efeito de pele nos poços e/ou no sistema de fraturas, visto que esse efeito tem tendência em gerar rebaixamentos maiores em consequência do atraso do escoa- 
mento do aquífero para o poço, no caso dos poços bombeados, ou da matriz rochosa para o sistema de fraturas (MOENCH, 1984).

Resultados semelhantes foram encontrados por Pereira e Almeida (1995), quando estes analisaram testes de bombeamento em regiões de ocorrência de aquíferos fraturados. Conforme os autores, a aplicação dos métodos desenvolvidos para sistemas de dupla porosidade apresentou melhor ajuste quando foram considerados os efeitos de pele, ou seja, o método de Moench.

Importante ressaltar que o efeito de pele consiste no retardo do fluxo da matriz para as fraturas e/ou das fraturas para o poço, devido à uma fina película que se deposita na superfície dos blocos em razão da precipitação de minerais ou dos processos de alteração da rocha, tendo influência na diminuição da permeabilidade (FIALHO; CHAMBEL; ALMEIDA, 1990). Com isso, pode-se pressupor que os rebaixamentos serão maiores, pois o volume de água disponível ao longo do tempo é menor. Considerando que no SASG a água é armazenada no conjunto de estruturas tectônicas, de resfriamento ou geradas no contato entre derrames, bem como nas camadas que podem apresentar maior porosidade (zonas vesiculares e amigdalóides) é possível que esse feito de pele ocorra com maior facilidade.

Os ajustes apresentados pelo método de Cooper \& Jacob e de Theis não foram satisfatórios, o que confirma que estes não são os melhores métodos a serem utilizados na avaliação de aquíferos fraturados (PAULA; CAMPOS, 2015; FERROUD, CHESNAUX; RAFINI, 2018; FERROUD; RAFINI; CHESNAUX, 2019). Ao observar as Figuras 4(a) a 4(f), 5(a) a 5(f) e 6(a) a $6(f)$, nota-se que as curvas teóricas não exibem similaridade com as experimentais, comprovando que os métodos não são eficazes em traduzir as descontinuidades de um meio heterogêneo e anisotrópico (WATERLOO HYDROGEOLOGY, 2017).

Os resultados obtidos especificamente em TB1 mostram que o poço bombeado (P1) retornou erros superiores quando comparado aos dois poços de observação (P2 e P3) em todos os métodos. Fetter (2001) destaca que, para testes em um único poço, devido ao regime turbulento gerado pelo bombeamento, os rebaixamentos serão muito maiores do que se fossem medidos em poços de observação, o que pode acarretar em imprecisões nos valores dos parâmetros hidrodinâmicos calculados. Portanto, pode-se associar a isso o motivo pelo qual as curvas de rebaixamento calculadas para os poços que sofreram o bombeamento foram menos ajustadas quando comparadas às curvas dos poços de observação. Fato que comprova que a avaliação das propriedades de um aquífero realizada somente através de dados de rebaixamento obtidos em poços bombeados pode apresentar resultados não muito precisos (MONTANHEIRO et al., 2017).

Em contrapartida, no TB2 essa observação não pode ser feita, visto que $\mathrm{P} 1$, que nesse caso se configura como um poço de observação, é o que apresenta os maiores erros. Deve-se salientar que, durante o TB2, o nível da água em P1 não apre- sentou rebaixamento contínuo ao longo do tempo, pois, entre os minutos 20 e 25 , este apresentou uma leve recuperação para logo em seguida voltar a decair. Esse aumento do nível da água pode estar relacionado com a presença de estruturas do reservatório fraturado que não estão ligadas aos demais poços e, desse modo, complementam a reserva de água disponivel a P1. Porém, a confirmação dessas informações depende da identificação das estruturas do poço através da realização de uma perfilagem geofísica, por exemplo, o que não foi o foco deste estudo. A variação do nível da água em P1 durante o TB2, na contramão do que era esperado, fez com que esse ponto não seguisse a tendência da curva de rebaixamento. Nas Figuras 5(a), 5(d), 5(g) e 5(j) é possível observar que nenhum dos métodos utilizados nesse estudo obteve um ajuste razoável para tal situação. Por esse motivo, TB2 foi o teste que, em média, apresentou os maiores erros de ajuste, com exceção do método de Cooper \& Jacob, cujos maiores erros ocorreram em TB3.

Com relação ao TB3, nota-se que para os métodos de aquíferos de dupla porosidade, o poço bombeado (P3) também foi o que apresentou o pior ajuste. Porém, para os métodos clássicos, isso não se repetiu. Nesse caso, P3 apresentou o melhor ajuste dentre os 3 poços monitorados, pois, como pode-se perceber nas Figuras 6(c) e 6(f), seu comportamento foi o que mais se aproximou do comportamento de um aquífero homogêneo.

Segundo Ahmed e Mckinney (2005), em poços onde há efeito de pele expressivo, as descontinuidades do aquífero podem ser mascaradas nas curvas de rebaixamento, estando estas sujeitas a serem diagnosticadas como representantes de aquíferos homogêneos. Nesse sentido, percebe-se também que P3, em TB3, foi o poço bombeado que obteve os maiores erros dentre os métodos de dupla porosidade e que os maiores desvios ocorreram nos tempos iniciais do teste, indicando efeito de pele. As curvas desse poço, em específico, podem ser visualizadas na Figura 6(i) e 6(I). De qualquer maneira, os erros obtidos através desses métodos continuam sendo consideravelmente menores do que dos métodos clássicos.

O melhor resultado para os dados de rebaixamento foi obtido no TB1, no qual os dados relativos a P2 analisados pelo modelo de Moench foram os que apresentaram os melhores ajustes aos dados experimentais. A curva gerada por tais dados pode ser visualizada na Figura 4(k). A avaliação da curva permite verificar que as fases inicial e intermediária do teste retornaram rebaixamentos levemente acima do que foi estimado através do método de Moench, principalmente nos dois primeiros pontos. Essa pequena divergência dos dados de rebaixamento também pode ser justificada pelo possível efeito de pele de fratura, conforme já discutido anteriormente.

A curva com o pior ajuste ocorreu no TB3, em P1, onde a soma dos erros quadrados foi igual a 23,08 com o modelo de Cooper \& Jacob. 0 ajuste pode ser observado na Figura 6(a). Ao observar as curvas geradas pelo método, percebe-se que a linha reta típica do modelo não ajusta, em nenhum momento, às curvaturas presentes nas curvas de rebaixamento. Portan- 
to, o método de Cooper \& Jacob, além de apresentar o ajuste com menor aderência, foi o que retornou os maiores erros gerais, com exceção no P1 em TB1 e no P2 em TB2.

\subsection{Resultados dos Testes de Recuperação}

Tabela 3 - Soma dos erros quadrados dos ajustes das curvas dos testes de recuperação Soma dos erros quadrados

\begin{tabular}{llllll}
\hline \multirow{2}{*}{ Teste de Recuperação } & Poço & Theis Recovery & Theis & Warren-Root & Moench \\
& & & & & 0,122 \\
TB1 & P1 & 0,640 & 0,639 & 0,498 & 0,164 \\
& P2 & 0,898 & 0,832 & 0,172 & 0,059 \\
TB2 & P3 & 3,034 & 2,857 & 0,116 & 0,062 \\
& P1 & 0,977 & 1,260 & 0,165 & 0,853 \\
TB3 & P2 & 1,810 & 2,336 & 0,888 & 0,180 \\
& P1 & 0,810 & 0,906 & 0,164 & 0,086 \\
\hline
\end{tabular}

Fonte: 0 autor (2020)

Figura 7 - Curvas de rebaixamento individuais de P1, P2 e P3 e seus respectivos ajustes para os métodos de Theis Recovery, Theis+Agarwal, Warren\&Root+Agarwal e Moench+Agarwal, nesta ordem, em TR1

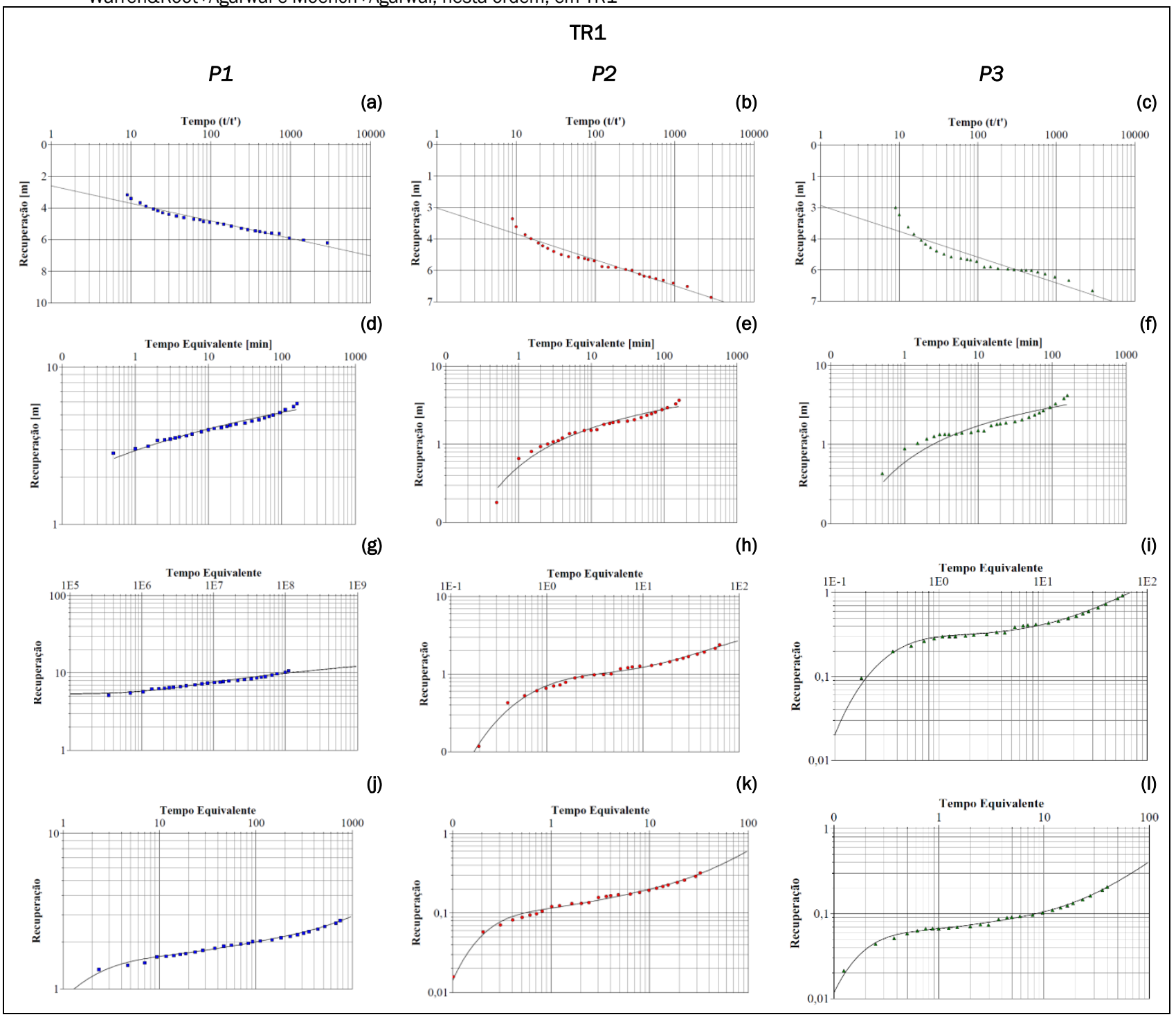

Fonte: Os autores (2020). 
Figura 8 - Curvas de rebaixamento individuais de P1, P2 e P3 e seus respectivos ajustes para os métodos de Theis Recovery, Theis+Agarwal, Warren\&Root+Agarwal e Moench+Agarwal, nesta ordem, em TR2

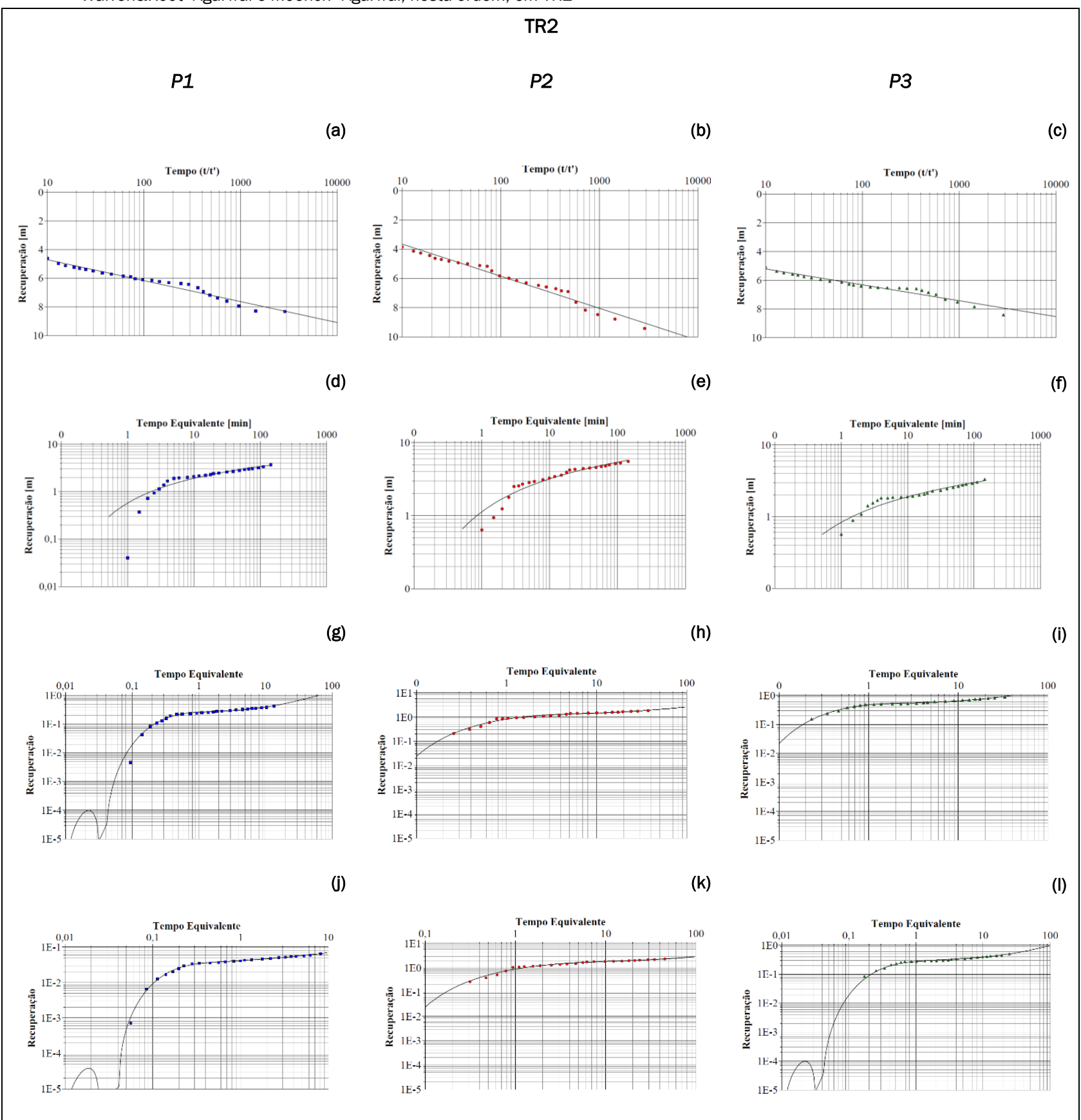

Fonte: Os autores (2020). 
Figura 9-Curvas de rebaixamento individuais de P1, P2 e P3 e seus respectivos ajustes para os métodos de Theis Recovery, Theis+Agarwal, Warren\&Root+Agarwal e Moench+Agarwal, nesta ordem, em TR3

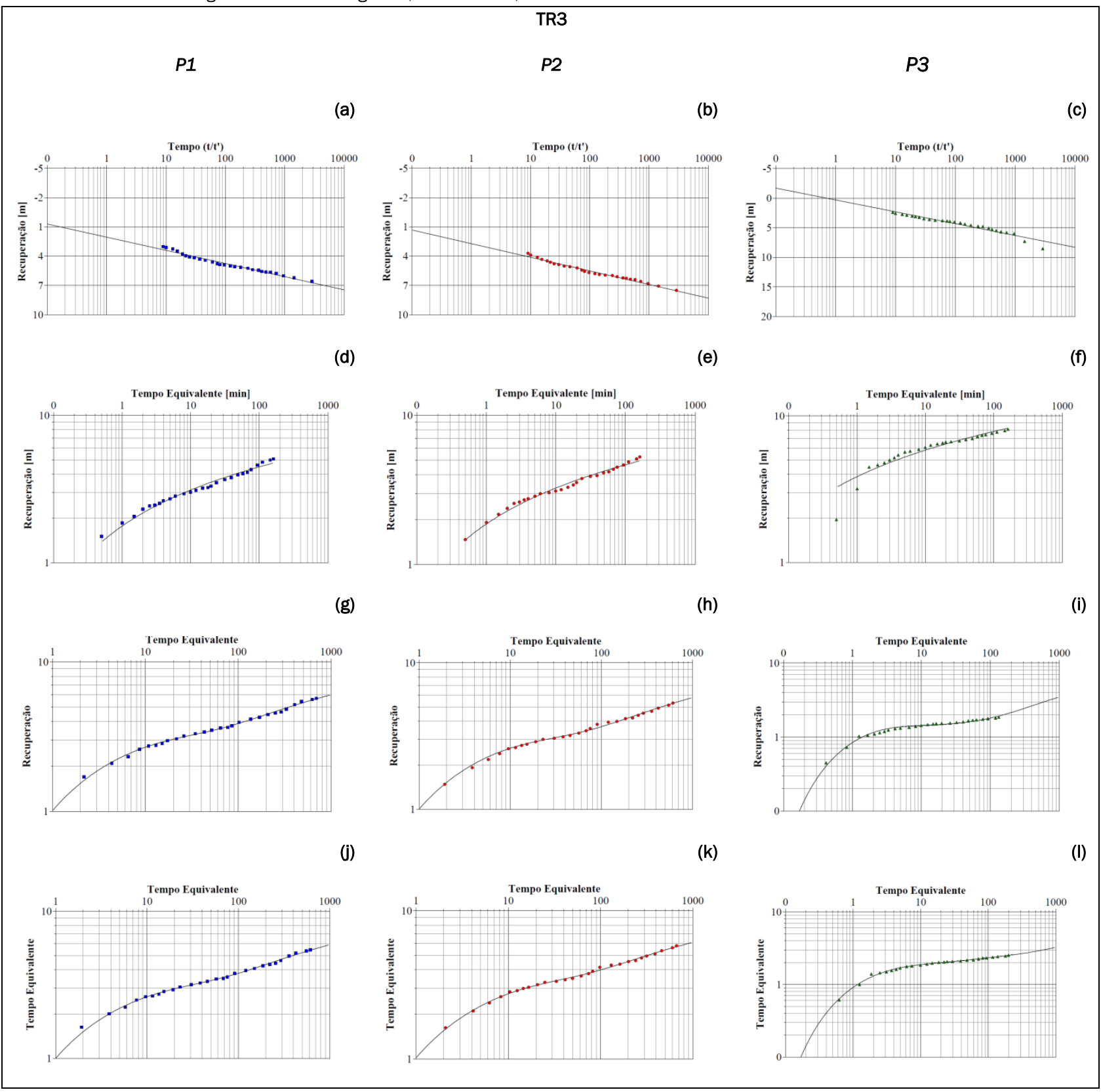

Fonte: Os autores (2020)

\subsubsection{Discussões sobre os Testes de Recuperação}

Verifica-se que os ajustes obtidos através dos dados de recuperação foram consideravelmente mais precisos do que os ajustes dos dados de rebaixamento, com exceção de P2 em TR2. Isso mostra que os resultados alcançados pelos dados de recuperação podem ser mais confiáveis do que os relativos aos dados de rebaixamento, conforme exposto por Waterloo Hydrogeology (2017). Considerando que a recuperação ocorre a taxas constantes, supõe-se que os métodos, em geral, são mais eficazes em representar o comportamento de aquíferos sem a interferência do bombeamento.

Contudo, mesmo que o bombeamento tenha cessado e que suas interferências no nível d'água sejam quase irrelevantes, apenas no TR1 não foram observados os maiores erros no poço previamente bombeado. Conforme Willmann et al. (2007), a recuperação do nível da água é sensível ao volume total retirado do aquífero no período de bombeamento, indicando que a influência deste na recuperação do nível da água não é completamente nula, o que auxilia no entendimento desses resultados.

Os ajustes das curvas de recuperação apresentaram as mesmas tendências das curvas de rebaixamento. Moench continua sendo o método com os menores erros, ressaltando-se P3 no TR1, presente na Figura 7(I), o qual representa o melhor ajuste obtido dentre todos os dados e métodos analisados.

Assim como verificado anteriormente, os erros do modelo de 
Warren-Root foram visivelmente muito similares aos de Moench. Analisando-se as curvas geradas pelos dois métodos, por exemplo P3 em TR1, que estão presentes nas Figuras7(i) e $7(\mathrm{I})$, observa-se que os ajustes são quase idênticos, apesar de o erro retornado por Warren-Root ser muito próximo ao dobro do erro de Moench.

Observa-se também que os momentos iniciais dos testes são os fatores que os métodos têm maior dificuldade em representar, de maneira similar ao que ocorre com os dados de rebaixamento, o que está em conformidade com o exposto por Agarwal (1980) em seu estudo, que afirma que testes de recuperação também sofrem influência dos efeitos de pele de poço e de fraturas.

Os métodos de recuperação desenvolvidos para aquíferos homogêneos (Theis+Agarwal e Recuperação de Theis) retornaram os ajustes menos aderentes, reafirmando a dificuldade destes em avaliar aquíferos heterogêneos e anisotrópicos, de acordo com o que foi evidenciado por Pereira e Almeida (1997). Porém, quando comparados aos erros apresentados pelos métodos clássicos aos dados de rebaixamento, os resultados obtidos através da recuperação foram melhores, com destaque para P1 em TR1, cujos erros foram próximos dos demais métodos. Dessa forma, não se deve descartar por completo a utilização desses métodos na avaliação dos dados de recuperação de aquíferos fraturados, porém deve ser preferível a utilização de métodos que retornem menores erros sempre que possível, neste caso, os métodos de dupla-porosidade. Os gráficos citados podem ser visualizados nas Figuras $7($ a) e $7(d)$.

Theis também foi o método que obteve o maior erro retornado pelos dados de recuperação, em TR3, P3 (Figura 9(f)). Nota-se que os dois primeiros pontos do teste são os mais distantes dos valores calculados pelo método de Theis, os quais foram superestimados, o que novamente aponta a incapacidade deste em representar sistemas mais complexos do que para os quais foi desenvolvido.

\subsection{Discussões Gerais}

A observação das curvas de rebaixamento dos testes de bombeamento, conforme Figura 3, permite verificar que os três apresentam um comportamento muito similar entre si. 0 fato de os poços de observação apresentarem curvas semelhantes às dos poços bombeados, independente das distâncias entre si, demonstra que estes estão inseridos dentro da mesma zona fraturada (CHO; FIACCO; DALY, 2004). Esse comportamento dos poços observados em relação ao poço bombeado também foi notado por Montanheiro et al. (2017) em seu estudo de caso realizado no SASG. Por esse motivo, entende-se que se houve alguma interferência do recurso hídrico superficial nos rebaixamentos, esta esteve presente em todos os três poços, não havendo diferença significativa entre eles. Contudo, é válido destacar também, que, embora os poços estejam próximos a um arroio, a tendência (se houvesse uma ligação entre as estruturas e a drenagem) seria de que as curvas de rebaixamento apresentassem uma certa estabilização, o que não foi observado nas curvas dos três poços. Dessa forma a possibilidade de conexão é difícil de ocorrer. De qualquer forma, a interação entre o recurso hídrico superficial e o aquífero estudado é foco da continuidade desta pesquisa, cujo principal objetivo é avaliar como ocorre a interação entre águas superficiais e subterrâneas no SASG e a sua influência no processo de recarga e nos padrões hidroquímicos da água.

Em relação aos resultados alcançados na comparação entre os métodos utilizados na avaliação dos testes de bombeamento, pode-se dizer que os métodos de dupla-porosidade aplicados ao SASG tendem a ser mais assertivos do que os métodos mais convencionais (Cooper \& Jacob e Theis). Esses resultados indicam que o SASG pode ser avaliado e considerado como um sistema de dupla porosidade, pois o fluxo e armazenamento de água pode ocorrer ao longo das estruturas tectônicas, bem como por outras estruturas que são geradas pelos processos de resfriamento e formação dos derrames, e também pela sobreposição de diferentes derrames. Assim, o modelo de dupla porosidade poderia ser considerado para todo o sistema. No entanto, em função das variações da estruturação dos aquíferos fraturados e da anisotropia, haverá situações onde o SASG pode ter outros comportamentos que não o de dupla porosidade. Por esse motivo, a aplicação desses resultados em outras regiões do SASG depende da realização de outros estudos que empreguem a mesma metodologia em uma rede maior de pontos de amostragem (poços) e também que abranjam locais de diferentes estruturas do aquífero, de maneira a avaliar se haverá diferenças em seu comportamento.

Por fim, é válido citar também a importância dos resultados para os processos de outorga de uso da água no estado do Rio Grande do Sul. As análises de testes de bombeamento no Brasil resumem-se ao ajuste das soluções de Cooper \& Jacob e de Theis aos dados de campo a fim de determinar os valores de transmissividade e coeficiente de armazenamento (CRUZ et al. 2019). Especialmente no estado, os testes de bombeamento que são apresentados ao poder público para fins de obtenção de outorga do uso da água são, geralmente, interpretados através do modelo de Cooper \& Jacob, justamente devido à facilidade de aplicação. Contudo, constatou-se, através dos resultados obtidos, que estes são os melhores métodos a serem utilizados na avaliação de aquíferos fraturados, tendo em vista que os ajustes obtidos às curvas de campo não foram satisfatórios. Portanto, entende-se que a utilização de tais métodos pode retornar parâmetros hidrodinâmicos superestimados ou subestimados, o que pode interferir na determinação da produtividade de um poço e, até mesmo, no valor estimado de volume de água armazenado no aquífero, influenciando, por sua vez, a gestão sustentável desse recurso hídrico.

\section{CONCLUSÃO}

Os resultados obtidos mostraram que o método que apresentou os menores erros tanto para os dados de rebaixamento quanto para os dados de recuperação foi o modelo de dupla 
porosidade com efeito de pele de Moench. 0 método de Warren \& Root apresentou erros bem próximos aos de Moench, porém ligeiramente superiores. Os ajustes obtidos através dos métodos clássicos não foram satisfatórios, tendo em vista que estes foram os que retornaram os maiores erros, comprovando a ineficiência desses em traduzir as descontinuidades de meios heterogêneos e anisotrópicos.

Além disso, foi possível confirmar que a avaliação de aquíferos através dos dados de rebaixamento obtidos em poços bombeados apresenta imprecisões, considerando que estes apresentaram erros superiores quando comparados aos poços de observação. A análise dos resultados mostrou que o bombeamento também exerce influência na recuperação do nível da água, uma vez que os poços previamente bombeados também retornaram erros superiores aos erros obtidos através dos poços observados. Todavia, os ajustes obtidos através dos dados de recuperação foram mais precisos, indicando que estes realmente geram resultados mais confiáveis do os relativos aos dados de rebaixamento.

Em suma, os resultados obtidos elucidaram algumas questões relativas às avaliações feitas a partir da execução de testes de bombeamento. A aplicação de diferentes modelos na análise de dados de rebaixamento gera resultados distintos, 0 que pode impactar, por exemplo, os processos de outorga da água subterrânea e a determinação da produção dos poços na região.

\section{AGRADECIMENTOS}

Os autores agradecem à Fundação de Amparo à Pesquisa do Estado do Rio Grande do Sul (FAPERGS) pelo apoio financeiro, ao Instituto de Saneamento Ambiental (ISAM) e Universidade de Caxias do Sul (UCS) pela infraestrutura e apoio institucional à pesquisa, e ao Instituto de Pesquisas Hidráulicas (IPHUFRGS) pela colaboração nos trabalhos realizados.

\section{REFERÊNCIAS}

AGARWAL, Ram G.. A new method to account for producing time effects when drawdown type curves are used to analyze pressure buildup and other test data. SPE Annual Technical Conference And Exhibition, Dallas, v. 9289, n. 1, p. 1-20, set. 1980. Society ofpetroleumengineers. $\underline{\text { http://dx.doi.org/10.2118/9289-ms. }}$ Disponível $\mathrm{em}$

https://blasingame.engr.tamu.edu/z zcourse archive/p648 19 a/p648_19a_lectures_(working lectures)/20190130_p648_19 a lec 06 spe $009289 \% 5$ bpdf\%5d.pdf. Acesso em: 05 jun. 2020.

AHMED, Tarek; MCKINNEY, Paul D. Well Testing Analysis. Advanced Reservoir Engineering, [s.l.]: Elsevier, v. 1, n. 1, p. 1 147, jan. 2005. http://dx.doi.org/10.1016/b978-0750677332/50003-4. Disponíve https://www.sciencedirect.com/science/article/pii/B97807506 77332500034. Acesso em: 05 jun. 2020.

AQUIFERTEST: Pumping \& slug test analisys, interpretation \& visualization software. Versão Pro 7.0. Waterloo, Canada: Waterloo Hydrogeology Co., 2017.

BEAR, Jacob. Hydraulic of Groundwater. 1 ed. Mineola: Dover Publications Inc., $1979 . \quad$ Disponível em:
https://www.scribd.com/read/271567645/Hydraulics-ofGroundwater. Acesso em: 27 mar. 2020.

BORTOLIN, Taison Anderson et al. Hidrogeologia e hidroquímica dos aquíferos fraturados associados às rochas vulcânicas ácidas do município de Carlos Barbosa (RS). Ambiente\&Água: An Interdisciplinary Journal of Applied Science, Taubaté, v. 9, n. 1, p. 5567, mar. 2014. Trimestral. Instituto de Pesquisas Ambientais em Bacias Hidrograficas (IPABHi). https://doi.org/10.4136/ambiagua.1270. Disponivel em: https://www.redalyc.org/pdf/928/92830124007.pdf. Acesso em: 23 mar. 2020.

CHO, H. Jean; FIACCO, R. Joseph; DALY, Matthew H. Pumping test analysis in a fractured crystalline bedrock. In: Proceedings of 2004 US EPA/National Ground Water Association Fractured Rock Conference: State of the Science and Measuring Successin Remediation. 2004. p. 161-172.

CLASS FINANCIAL ANALYST. Sum of squares: a statistical tool that is used to identify the dispersion of data. 2020. Disponivel em: https://corporatefinanceinstitute.com/resources/knowledge/other/sum-of-squares/. Acesso em: 28 maio 2020.

COMPANHIA DE PESQUISA DE RECURSOS MINERAIS. Execução de testes de bombeamento em poços tubulares: Manual prático de orientação. [S. I.]: CPRM, 1998. Disponível em: http://dspace.cprm.gov.br/ispui/bitstream/doc/16635/1/Testes Bombeamento Pocos Tubulares.pdf. Acesso em: 21 mai. 2020.

CONGRESSO BRASILEIRO DE ÁGUAS SUBTERRÂNEAS, 12. 2002, Florianópolis. Comportamento do Aquífero Fissural na Microbacia do Córrego da Cachoeira, Município de Vinhedo (SP). [São Paulo]: ABAS, 2002.Disponivel em:https://aguassubterraneas.abas.org/asubterraneas/article/view/22065. ACESSO EM: 31 MAR. 2020.

COOPER JR, H. H.; JACOB, Charles Edward. A generalized graphical method for evaluating formation constants and summarizing wellfield history. Eos, Transactions American Geophysical Union, v. 27, n. 4, p. 526-534, 1946. Disponível em: https://www.nrc.gov/docs/ML1429/ML14290A600.pdf.

Acesso em: 13 dez. 2020. https://doi.org/10.1029/TR027i004p00526

CRUZ, Fábio et al. Análise derivativa de testes de bombeamento em aquíferos fissurais no município de Jundiaí/SP. Revista do Instituto Geológico, São Paulo, v. 40, n. 3, p. 13-26, 31 dez. 2019. http://dx.doi.org/10.33958/revig.v40i3.673. Disponível em: http://www.ppegeo.igc.usp.br/index.php/rig/article/view/13535 . Acesso em: 15 abr. 2020.

DUTRA, Tuane de Oliveira. Avaliação da explotação de poços tubulares, no Sistema Aquífero Serra Geral, por sistema de monitoramento automatizado. 2016. Dissertação (Mestrado) - Programa de Pós-graduação em Recursos Hídricos e Saneamento Ambiental, Instituto de Pesquisas Hidráulicas, Universidade Federal do Rio Grande do Sul, Porto Alegre, 2016. Disponível em: https://lume.ufrgs.br/handle/10183/143909. Acesso em: 23 mar. 2020.

FEITOSA, Fernando A. C. et al. Hidrogeologia: conceitos e aplicações. Rio de Janeiro: CPRM, 2008.

FELLER, Moshe et al. Aquífero Guarani: manual de teste de bombeamento. [S. I.: s. n.], 2009. Disponível em: https://www.mma.gov.br/publicacoes/agua/category/42-recursos-hidricos.html?download=879: manual-de-teste-de-bombeamento . Acessoem: 21 maio 2020.

FERROUD, Anouck; RAFINI, Silvain; CHESNAUX, Romain. Us 
ing flow dimension sequences to interpret non-uniform aquifers with constant-rate pumping-tests: a review. Journal of $\mathrm{Hy}$ drology X, v. 2, n. 1, p. 1-25, jan. 2019. Mensal. http://dx.doi.org/10.1016/i.hydroa.2018.100003. Disponivel em: $\quad$ https://www.sciencedirect.com/science/article/pii/S2589915518300038. Acesso em: 03 jun. 2020.

FIALHO, A.; CHAMBEL, A.; ALMEIDA, C. Caracterização hidráulica de aquíferos fracturados por modelos de porosidade dupla no concelho de Evora. In: CONGRESSO DA ÁGUA. [Anais...], Lisboa, 1990. Disponível em: https://www.researchgate.net/publication/303919195 CARACTERIZACAO HIDRAULICA DE AQUIFEROS FRACTURADOS POR MODELOS DE POROSIDADE DUPLA NO CONCELHO DE EVORa Acesso em: 15 nov. 2020.

FOREST GIS. Download GIS. Forestgis geodatabase. [S. I.], [2017]. Arquivo GIS/Shapefile. Disponível em: http://forestgis.com/download-de-shapefiles/. Acesso em: 19 maio 2020.

FRENZEL, Matheus Gorniski. Caracterização hidrogeológica do sistema aquífero serra geral (sasg) na região de garibaldi, RS. 2017. TCC (Graduação) - Curso de Geologia, Geociências, Universidade Federal do Rio Grande do Sul, Porto Alegre, 2017. Disponivel em: https://lume.ufrgs.br/handle/10183/172320. Acesso em: 23 mar. 2020.

GOOGLE EARTH PRO. Versão 7.3.3.7699. Mountain View, Califórnia: Google LLC, Alphabet Inc., 2020.

KUANG, Xingxing et al. A review of specific storage in aquifers. Journal of Hydrology, [s.I.]: ELSEVIER, v. 581, p. 1-20, fev. 2020. Mensal. http://dx.doi.org/10.1016/j.jhydrol.2019.124383. Disponivel em: https://www.sciencedirect.com/science/article/pii/S0022169419311187. Acesso em: 22 abr. 2020.

LIN, Lixiang; LIN, Haili; XU, Yongxin. Characterisation of fracture network and groundwater preferential flow path in the Table Mountain Group (TMG) sandstones, South Africa. Water SA, [S.I.]: Academy of Science of South Africa, v. 40, n. 2, p. 263-272, 27 mar. 2014. Trimestral. http://dx.doi.org/10.4314/wsa.v40i2.8 Disponivel em: https://www.ajol.info/index.php/wsa/article/view/102219. Acesso em: 31 mar. 2020.

MOENCH, Allen F. Double-porosity models for a fissured groundwater resevoir with fracture skin. Water Resources Rese-

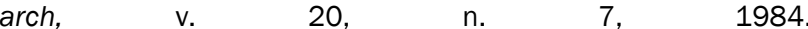
https://doi.org/10.1029/WR020i007p00831.

MONTANHEIRO, Filipe et al. Testes de bombeamento como requisitos para elaboração de modelos hidrogeológicos conceituais: estudo de caso no Aquífero Serra Geral. Águas Subterrâneas, mar. 2017. http://dx.doi.org/10.14295/ras.v0i0.28845. Disponivel em: https://aguassubterraneas.abas.org/asubterraneas/article/view/28845. Acesso em: 23 mar. 2020.

PAULA, Thiago de; CAMPOS, José. Aquíferos com fluxos controlados simultaneamente por porosidade intergranular e planar: aplicação a rochas metassedimentares do Alto Paraguai, MT. Revista Brasileira de Recursos Hídricos, v. 21, n. 1, p. 11-24, 25 abr. 2016. http://dx.doi.org/10.21168/rbrh.v21n1.p11-24. Disponível em: https://www.scielo.br/scielo.php?pid=S2318$03312016000100011 \&$ script=sci arttext\&ting=pt . Acesso em: 03 jun. 2020
PEREIRA, Maria Rosário; ALMEIDA, Carlos. Interpretação de ensaios de caudal de aquíferos fracturados em Trás-os-Montes Oriental (Portugal) por modelos de porosidade dupla e por métodos clássicos. Hydrogeology Of Hard Rocks, p. 15-29, 1997. Disponível em: https://www.researchgate.net/publication/272825567_Interpretacao_de_ensaios_de_caudal de aquiferos fracturados em Tras-os-Montes Oriental Portugal_por_modelos_de_porosidade_dupla_e_por_metodos_classicos. Acesso em: 01 jun. 2020.

REGINATO, Pedro Antônio Roehe; STRIEDER, Adelir José. Caracterização estrutural dos aquíferos fraturados da Formação Serra Geral na região nordeste do estado do Rio Grande Do Sul. Revista Brasileira de Geociências, São Paulo: [s. n.], 2006. Disponivel

http://ppegeo.igc.usp.br/index.php/rbg/article/view/9349 em: Acesso em: 23 mar. 2020

SEN, Zekai.Practical and applied hydrogeology.1 ed. Istanbul, Turquia: Elsevier, 2015. Disponível em: https://www.scribd.com/read/282658904/Practical-and-Applied-Hydrogeology\# . Acesso em: 09 jun. 2020.

SUN, Kerang. Formulating surrogate pumping test data sets to assess aquifer hydraulic conductivity. Journal of Hydrology X, [S.I.]: ELSEVIER, v. 1, p. 1-5, dez. 2018. Mensal. http://dx.doi.org/10.1016/j.hydroa.2018.100004. Disponivel em: $\quad$ https://www.sciencedirect.com/science/article/pii/S258991551830004X. Acesso em: 22 abr. 2020.

TANG, Yiqunet al. Groundwater Engineering.1 ed. Shanghai, China: SPRINGER, 2016. https://doi.org/10.1007/978-981-100669-2_1Disponível em: https://www.scribd.com/document/353853043/Groundwater-Engineering-Springer-VerlagBerlin-Heidelberg-2016. Acesso em: 09 jun. 2020.

THEIS, Charles V. The relation between the lowering of the piezometric surface and the rate and duration of discharge of a well using ground-water storage. Eos, Transactions American Geophysical Union, v. 16, n. 2, p. 519-524, 1935. https://doi.org/10.1029/TR016i002p00519. Disponivel em: https://water.usgs.gov/ogw/pubs/Theis-1935.pdf . Acesso em: 13 dez. 2020

WARREN, J. E.; ROOT, P. J. The behavior of naturally fractured reservoirs. Society of Petroleum Engineers Journal, Pittsburgh: [s. n.], p. 245-255, set. 1963. https://doi.org/10.2118/426-PA. Disponivel em: https://www.onepetro.org/download/journalpaper/SPE-426-PA?id=journal-paper\%2FSPE-426-Pa. Acesso em: 08 jun. 2020

WATERLOO HYDROGELOGY. AquiferTest Pro 7.0: Pumping \& Slug Test Analisys, Interpretation \& Visualization Software: User's Manual. Waterloo, Canada: Waterloo Hydrogeology, 2017.

WILLMANN, M. et al. On the meaning of the transmissivity values obtained from recovery tests. Hydrogeology Journal, [S.L.], v. 15, n. 5, p. 833-842, 1 fev. 2007. Springer Science and Business Media LLC. http://dx.doi.org/10.1007/s10040-006-0147-8.

Disponivel em: https://www.researchgate.net/publication/226185223 On the Meaning of the Transmissivity Values_Obtained_from_Recovery_Tests. Acesso em: 15 nov. 2020. 